Int. J. Electrochem. Sci., 14 (2019) 4338 - 4349

International Journal of

ELECTROCHEMICAL

SCIENCE

WWW.electrochemsci.org

\title{
Effect of Current Density on Characteristics of 2024 Aluminum Alloy Microarc Oxidation Coatings with Titanium Dioxide Particles
}

\author{
Ping Wang ${ }^{1,2}$, Wei Xiao Wei ${ }^{1, *}$, Jun Pu ${ }^{2}$, Xiao Long Zhou ${ }^{2}$, Wen Jie Cao ${ }^{2}$, You Tao Xiao ${ }^{2}$, \\ $\mathrm{Ze} \mathrm{Yu} \mathrm{Gong}{ }^{2}$, Jie Hu ${ }^{2}$ \\ ${ }^{1}$ The Postdoctoral Station at Xihua University Based on Collaboration Innovation Center of Sichuan \\ Automotive Key Parts, School of Materials Science and Engineering, Xihua University, Chengdu, \\ 610039, China \\ ${ }^{2}$ School of Materials Science and Engineering, Southwest Petroleum University, Chengdu, 610500, \\ China \\ *E-mail: weixiaowei90@yeah.net
}

doi: $10.20964 / 2019.05 .30$

Received: 4 January 2019 / Accepted: 23 February 2019 / Published: 10 April 2019

Ceramic coatings were deposited on a 2024 aluminum alloy by microarc oxidation (MAO) in a silicate electrolyte system containing $2 \mathrm{~g} / \mathrm{L}$ nano- $\mathrm{TiO}_{2}$ particles at different current densities $(1,2.5,5,7.5$ and $10 \mathrm{~A} / \mathrm{dm}^{2}$ ). The oxidation voltage, surface and cross-section morphologies and corrosion resistance of the coatings were studied. The results indicated that the voltage increased and facilitated the growth rate of MAO coatings so that the coatings thickened as the current density increased. The size of the micropores on the coating surface first increased and then decreased, and the shape changed from a strip-shaped hole to a round hole. The microhardness and the coating adhesive strength improved with increasing current density, whereas the corrosion resistance of the coatings decreased first and then increased. The coatings were mainly composed of $\gamma-\mathrm{Al}_{2} \mathrm{O}_{3}, \mathrm{SiO}_{2}$, mullite, $\mathrm{TiO}_{2}$ and a small amount of $\alpha-\mathrm{Al}_{2} \mathrm{O}_{3}$. As a whole, the discharge energy increased with increasing current density, and the microarc oxidation reactions became more intense, which contributed to the variation in the characteristics of the coatings.

Keywords: Microarc oxidation; Current density; 2024 aluminum alloy; $\mathrm{Nano}_{-} \mathrm{TiO}_{2}$ particles

\section{FULL TEXT}

(C) 2019 The Authors. Published by ESG (www.electrochemsci.org). This article is an open access article distributed under the terms and conditions of the Creative Commons Attribution license (http://creativecommons.org/licenses/by/4.0/). 